\title{
The performance of serum cryptococcal capsular polysaccharide antigen test, histopathology and culture of the lung tissue for diagnosis of pulmonary cryptococcosis in patients without HIV infection
}

This article was published in the following Dove Press journal:

Infection and Drug Resistance

\author{
Ying Zhou',* \\ Peng-Cheng Lin',* \\ Jun-Ru Ye' \\ Shan-Shan Su' \\ Li Dong' \\ Qing $W u^{2}$ \\ Han-Yan Xu' \\ Yu-Peng Xie' \\ Yu-Ping Lil \\ 'Department of Pulmonary and \\ Critical Care Medicine, The First \\ Affiliated Hospital of Wenzhou \\ Medical University, Wenzhou 3250I5, \\ Zhejiang, China; ${ }^{2}$ The Center of \\ Laboratory and Diagnosis, The First \\ Affiliated Hospital of Wenzhou \\ Medical University, Wenzhou 3250I5, \\ Zhejiang, China \\ *These authors contributed equally to \\ this work
}

Correspondence: Yu-Peng Xie; Yu-Ping Li Department of Pulmonary and Critical Care Medicine, The First Affiliated Hospital of Wenzhou Medical University, South Baixiang, Ouhai District, Wenzhou 325015 , Zhejiang, China

Tel/Fax+8657755579273

Email xieyp2002@wzhospital.cn; wzliyp@163.com
Background: Clinicians may fail to make an early diagnosis of pulmonary cryptococcosis (PC) without HIV infection. Serum cryptococcal capsular polysaccharide antigen (CrAg) test, histopathology and culture of lung tissue play different roles in diagnosis of PC.

Objective: To investigate the performance of serum CrAg test, histopathology and culture of the lung tissue in diagnosis of PC without HIV infection.

Patients/methods: From January 2011 to September 2017, patients with proven PC were recruited from a teaching hospital in southern China. Those patients with HIV infection, PC confirmed by surgery or $\mathrm{PC}$ with probable or possible diagnosis were excluded from the study. Latex agglutination test and $\mathrm{CrAg}$ lateral flow assay were used for detection of serum $\mathrm{CrAg}$. Lung biopsy and needle aspiration were performed under computed tomography guidance.

Results: Eighty-nine patients with proven PC including 41 male (46.1\%) and 48 female (53.9\%) were enrolled. Fifty-one (57.3\%) patients had underlying disease. Positive CrAg test was found in 83 (93.3\%) cases. Among six cases with negative CrAg test, PC was confirmed by histology in two cases and positive culture in four cases. The histopathological results of $77(86.5 \%)$ cases revealed cryptococcal granuloma and 12 cases showed chronic inflammation, which was confirmed by positive culture. Among 65 cases, the diseased tissue of $46(70.8 \%)$ cases presented Cryptococcus neoformans in the culture and one case was diagnosed with lung cancer coexisting with PC. Conclusion: Our findings showed that serum CrAg test is rapid and sensitive in diagnosing PC, histology is important for confirming PC and culture plays a complementary role. Biopsied lung tissue should be submitted for cultures whenever feasible.

Keywords: pulmonary cryptococcosis, fungal infection, Cryptococcus neoformans, cryptococcal capsular polysaccharide antigen, diagnosis

\section{Introduction}

Pulmonary cryptococcosis (PC) is a potentially serious fungal infection, which is caused by inhalation of Cryptococcus neoformans or Cryptococcus gattii. Due to their high affinity for the central nervous system (CNS), Cryptococcus spp. are associated with the risk of cryptococcal meningitis which has a high mortality. PC is more common in immunocompromised patients, but also occurs in immunocompetent hosts ${ }^{1}$ in whom its diagnosis is either false negative or easily missed because of its nonspecific symptoms and less risk factor. Recently, the incidence of PC in immunocompetent hosts has risen rapidly, with most of the PC cases in 
China being reported without apparent underlying disease. ${ }^{2}$ The diagnosis of PC depends on serology, histopathology and mycological culture. The serum cryptococcal capsular polysaccharide antigen $(\mathrm{CrAg})$ test, that has been used to diagnose PC both in developed and developing nations due to its rapid turnaround time and low costs, is a sensitive and specific test for the diagnosis of cryptococcosis in immunocompromised patients. ${ }^{3}$ However, the sensitivity of the serum CrAg test for detecting PC in patients with isolated PC is not very high. ${ }^{4}$ Mycological culture of lung tissue and histopathology to identify Cryptococcus yeast cells or cryptococcal granuloma are the main methods to confirm the diagnosis of PC. The accurate sensitivity of histopathology in PC patients without HIV infection for which lung tissue is obtained under computed tomography (CT) guidance is not clear. Additionally, mycological culture results usually require up to 3-4 days. Therefore, the value of culture of lung tissue in $\mathrm{PC}$ is not clear. The objective of this study is to investigate the performance of serum $\mathrm{CrAg}$ test, histopathology and culture of the lung tissue obtained from biopsy under CT guidance in diagnosis of PC without HIV infection by retrospectively analyzing the patients with confirmed PC from a teaching hospital in southern China.

\section{Patients and methods}

\section{Patients}

From January 2011 to September 2017, all patients with diagnosis of PC confirmed at the First Affiliated Hospital of Wenzhou Medical University were retrospectively reviewed by a computer-assisted search of medical records. Those patients with HIV infection, PC confirmed by surgery or PC with probable or possible diagnosis were excluded from the study. The flowchart for the selection of the study population is shown in Figure 1.

Proven $\mathrm{PC}^{5}$ is defined as isolation or detection of Cryptococcus by lung specimen culture and/or cryptococcal granuloma by histopathological examination.

\section{Methods}

\section{Data collection}

The following data were recorded: age, sex, humoral and cell immune parameters, underlying diseases and clinical manifestations, features of CT scan, serum CrAg test result, result of histopathology and microbiological culture of lung tissue obtained under CT guidance. The follow-up information of the patients was obtained on regular clinic visit and by telephone conversation. This retrospective study was approved by the Ethics Committee of the First Affiliated Hospital of Wenzhou Medical University (2017074). Informed consent was waived because this was a retrospective study and there was no modification in patient management. All personal information was encrypted in the database, and patient data accessed were de-identified. There was no breach of privacy.

\section{Serum CrAg test}

From January 2011 to September 2017, latex agglutination (LA) test (Latex-Cryptococcus Antigen Detection System; IMMY Inc.) was used for semiquantitative detection of the CrAg in serum and cerebrospinal fluid. After January 2015, CrAg lateral flow assay (CrAg LFA; IMMY Inc.) was also used for rapid qualitative detection of the $\mathrm{CrAg}$ in serum

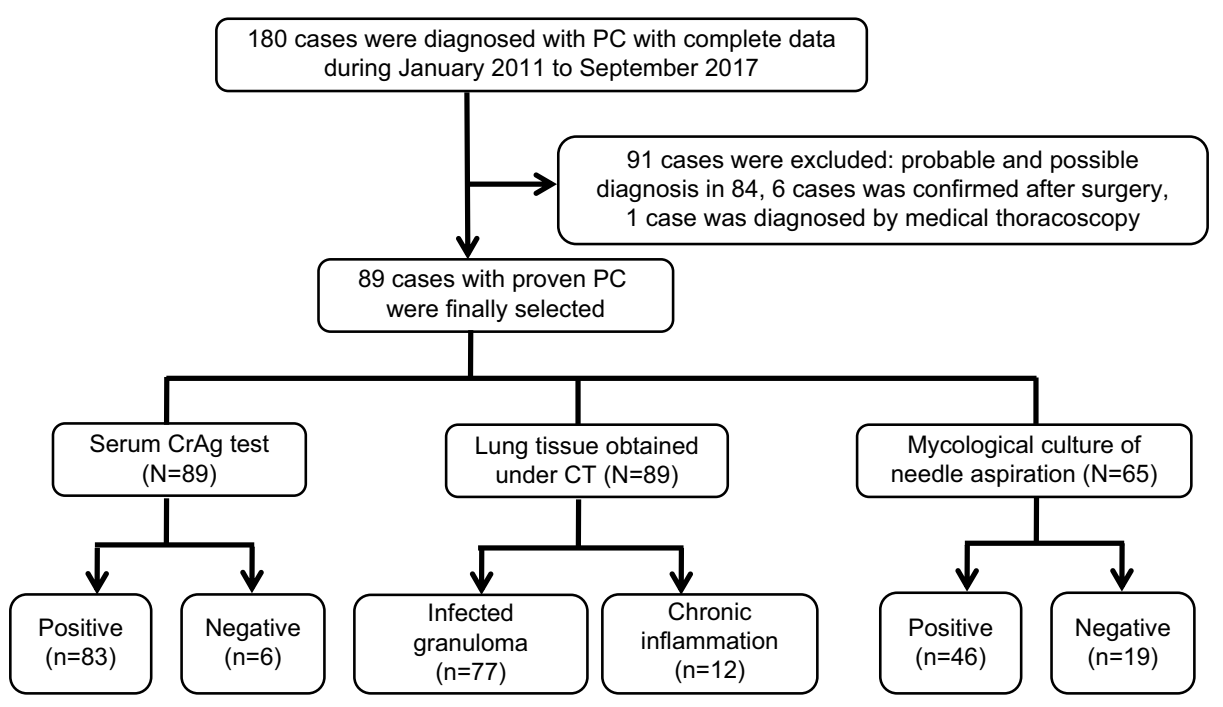

Figure I Flowchart of the study population and data of positive and negative cases of different diagnostic methods.

Abbreviations: $\mathrm{CrAg}$, cryptococcal capsular polysaccharide antigen; CT, computed tomography; PC, pulmonary cryptococcosis. 
according to the manufacturer's instructions; if the result was positive, semiquantitative LA test was carried out.

\section{CT-guided lung biopsy and needle aspiration (NA)}

The procedure was similar to that described by Moore. ${ }^{6}$ Under the guidance of helical multidetector row CT fluoroscopy, biopsies were performed using a coaxial technique with a 19-gauge thin-wall coaxial introducer needle, and core biopsies (CBs) were performed with an 18-gauge automated cutting needle biopsy gun (FINECORE; Dr.Japan Co., Ltd.). After $\mathrm{CB}$, NA was performed. A $10 \mathrm{~mL}$ syringe was connected with a thin-wall outer needle, moved up and down slightly and $2-5 \mathrm{~mL}$ (according to the nodule size) of secretion was drawn from the diseased tissue. The obtained tissue was fixed on formalin and sent for pathological examination.

The liquid obtained from the aspiration was inoculated into BACTEC bottles (Becton, Dickinson and Company, Franklin Lakes, NJ, USA) for bacterial, fungal and mycobacterial culture (Figure S1). The samples were also placed on a glass slide for cytological and microbiological tests.

The detailed procedure is shown in Video S1. Chest $\mathrm{X}$-rays were obtained after the procedure to detect possible pulmonary complications.

\section{Statistical analysis}

All values are expressed as mean $\pm \mathrm{SD}$. According to the result of the positive cases, the sensitivity of the different methods of PC diagnosis was calculated.

\section{Results}

\section{Patient characteristics}

As shown in the study flowchart, a total of 180 patients with PC were selected. Ninety-one patients were excluded, and 89 patients with proven PC including 41 male (46.1\%) and 48 female $(53.9 \%)$ were included in the final analysis. Fiftythree patients had received lumbar puncture. Four patients had PC coexisting with cryptococcal meningitis. The mean age of the selected patients was $48 \pm 14$ (range 16-85) years.

Fifty-one $(57.3 \%)$ patients had underlying disease. The most common diseases include the following: 18 (20.2\%) patients had cardiovascular disease, 10 (11.2\%) had diabetes mellitus, 11 (12.4\%) had chronic liver diseases and nine (10.1\%) had neoplasm. Twenty-one (23.6\%) patients were asymptomatic and detected accidentally by screening. The most common symptoms were cough and sputum production, while fever was found in $16(18 \%)$ patients. The characteristics and clinical manifestations of all patients with PC at diagnosis are shown in Table 1.

\section{Laboratory test and radiological results}

The laboratory test results of majority of patients were in normal range; the details are shown in Table 2 . The frequent radiological abnormality was one or more pulmonary nodules, with predominant lower lobe involvement and peripheral distribution. The radiological manifestations of patients with proven PC are shown in Table 3.

\section{Diagnostic methods for PC}

All the patients received the serum $\mathrm{CrAg}$ detection and percutaneous lung biopsy under CT guidance. NA was performed in 65 cases at the same time and sent for mycological culture.

Of the 89 patients, 83 (93.3\%) had positive CrAg test. The average titer was 1:128. Among six cases with negative CrAg test, PC was confirmed by histology in two cases and positive mycological culture in four cases; the details are shown in Table 4.

Of the 89 patients, histopathological results of $77(86.5 \%)$ patients revealed cryptococcal granuloma, while the other 12 cases showed chronic inflammation. Forty-six (70.8\%)

Table I Characteristics and clinical manifestations of patients with proven PC $(n=89)$

\begin{tabular}{|l|l|}
\hline Characteristics & $\begin{array}{l}\text { No. of } \\
\text { patients (\%) }\end{array}$ \\
\hline Age (years), mean \pm SD & $48 \pm 14$ \\
Gender & $41(46.1)$ \\
Male & $48(53.9)$ \\
Female & \\
Underlying diseases & $10(11.2)$ \\
Diabetes & $18^{\mathrm{a}}(20.2)$ \\
Cardiovascular disease & $9(10.1)$ \\
Neoplasm & $11(12.4)$ \\
Chronic liver disease & $6(6.7)$ \\
Using steroid for more than 2 weeks & $6(6.7)$ \\
Using immunosuppressant for more than 2 weeks & $16^{\mathrm{b}}(17.9)$ \\
Others & $38(42.7)$ \\
No underlying diseases & \\
Clinical symptoms & $52(58.4)$ \\
Cough & $35(39.3)$ \\
Sputum & $16(18.0)$ \\
Chest pain & $16(18.0)$ \\
Fever & $13(14.6)$ \\
Dyspnea & $3(3.4)$ \\
Hemoptysis & $21(23.6)$ \\
No symptoms & $53(59.6)$ \\
Lumbar puncture & $4(4.5)$ \\
Combination of cryptococcal meningitis & \\
\hline
\end{tabular}

Notes: Data are positive patients over total patients (\%), unless otherwis indicated. ${ }^{a}$ Cardiovascular diseases include hypertension (I6), viral myocarditis (I) and arrhythmia (I). ' $\mathrm{O}$ ther underlying diseases include chronic gastritis (3), kidney stones (2), parotiditis (1), rheumatoid arthritis (2), pulmonary tuberculosis (3), uterine fibroid (2), appendicitis (2) and schizophrenia (I).

Abbreviation: PC, pulmonary cryptococcosis. 
Table 2 Laboratory examination results of patients with proven PC $(n=89)$

\begin{tabular}{|c|c|c|}
\hline Laboratory examination & $\begin{array}{l}\text { Counts of } \\
\text { peripheral } \\
\text { blood }\end{array}$ & $\begin{array}{l}\text { Normal } \\
\text { ranges }\end{array}$ \\
\hline Leukocyte $\left(\bar{x} \pm S D, \times 10^{9} / L\right)$ & $6.35 \pm 1.87$ & $3.50-9.50$ \\
\hline Neutrophil $\left(\bar{x} \pm S D, \times 10^{9} / L\right)$ & $3.93 \pm 1.63$ & $1.80-6.30$ \\
\hline Lymphocyte $\left(\overline{\mathrm{x}} \pm \mathrm{SD}, \times 10^{9} / \mathrm{L}\right)$ & $1.69 \pm 0.73$ & $1.10-3.20$ \\
\hline Hemoglobin $(\bar{x} \pm S D, g / L)$ & $134.07 \pm 18.35$ & $130-175$ \\
\hline Platelet $\left(\overline{\mathrm{x}} \pm \mathrm{SD}, \times 10^{9} / \mathrm{L}\right)$ & $241.07 \pm 65.46$ & $125-350$ \\
\hline Albumin $(\bar{x} \pm S D, g / L)$ & $40.49 \pm 4.62$ & $40.0-55.0$ \\
\hline Total protein $(\bar{x} \pm S D, g / L)$ & $70.30 \pm 6.46$ & $65.0-85.0$ \\
\hline Blood glucose $(\bar{x} \pm S D, \mathrm{mmol} / \mathrm{L})$ & $6.35 \pm 6.24$ & $3.90-6.10$ \\
\hline \multicolumn{3}{|l|}{ T-lymphocyte cell subsets ( $\bar{x} \pm S D, \%)$} \\
\hline $\mathrm{CD} 3$ & $72.13 \pm 10.09$ & $60.0-79.0$ \\
\hline CD4 & $41.48 \pm 8.99$ & $34.0-52.0$ \\
\hline CD8 & $24.67 \pm 7.92$ & $21.0-39.0$ \\
\hline CD4/CD8 & $1.91 \pm 0.90$ & \\
\hline CDI9 & $11.68 \pm 4.38$ & $5.0-18.0$ \\
\hline CD56 & $|3.48 \pm 8.9|$ & $7.0-40.0$ \\
\hline $\lg \mathrm{A}(\overline{\mathrm{x}} \pm \mathrm{SD}, \mathrm{g} / \mathrm{L})$ & $1.99 \pm 1.53$ & $0.70-4.00$ \\
\hline $\operatorname{lgM}(\bar{x} \pm S D, g / L)$ & $1.22 \pm 0.61$ & $0.40-2.30$ \\
\hline $\lg G(\bar{x} \pm S D, g / L)$ & $12.73 \pm 3.48$ & $7.00-16.00$ \\
\hline $\mathrm{C} 3(\overline{\mathrm{x}} \pm \mathrm{SD}, \mathrm{g} / \mathrm{L})$ & $1.05 \pm 0.18$ & $0.90-1.80$ \\
\hline $\mathrm{C} 4(\overline{\mathrm{x}} \pm \mathrm{SD}, \mathrm{g} / \mathrm{L})$ & $0.22 \pm 0.09$ & $0.10-0.40$ \\
\hline
\end{tabular}

Abbreviation: PC, pulmonary cryptococcosis.

Table 3 Radiological manifestations of patients with proven PC $(\mathrm{n}=89)$

\begin{tabular}{|l|l|}
\hline Radiological findings & No. of patients (\%) \\
\hline Abnormalities & $68(76.4)$ \\
Nodules & $18(20.2)$ \\
Masses & $38(42.7)$ \\
Consolidation & $13(14.6)$ \\
Cavity & $5(5.6)$ \\
Lymph node & $1(1.1)$ \\
Pleural effusion & $79(88.8)$ \\
Distribution & $10(11.2)$ \\
Lobe & \\
Segments & $44(49.4)$ \\
Site of lesion(s) & $16(18.0)$ \\
Upper lobe & $77(86.5)$ \\
Middle lobe & $46(51.7)$ \\
Lower lobe & \\
Multiple lobes $(\geq 2)$ & \\
\hline
\end{tabular}

Notes: Data are positive patients over total patients (\%). Nodules: a rounded or oval-shaped opacity $\leq 3 \mathrm{~cm}$ in diameter; masses: a rounded or oval-shaped opacity $>3 \mathrm{~cm}$ in diameter.

Abbreviation: PC, pulmonary cryptococcosis.

out of 65 cases presented $C$. neoformans in the culture of diseased tissue obtained under CT guidance. Among 41 cases, $21(51.2 \%)$ revealed Cryptococcus yeast on smear of the aspirated secretion. All the 12 patients found with chronic inflammation in histopathological examination presented with $C$. neoformans in culture and an established diagnosis. The chest CT scan of a 30-year-old female, with cough for 1 month, revealed a cavitary nodule, $25 \mathrm{~mm}$ in diameter, in the right lower lung (Figure 2). The serum CrAg test titer is 1:64. Histopathological examination of lung tissue obtained under CT guidance revealed lung cancer, and the culture of NA revealed $C$. neoformans growth and lung cancer coexisting with PC. Histopathology showed cryptococcal granuloma in 19 cases, and culture was negative in 16 cases while the culture of three patients revealed Staphylococcus epidermidis growth which was considered as contamination. The sensitivity of different diagnostic methods is shown in Table 5 .

\section{Treatment and outcome}

All the patients received antifungal treatment. Fluconazole was initially prescribed in 89 patients, the dosage of which was $384 \pm 77 \mathrm{mg} /$ day. Combination therapy was prescribed in five patients (fluconazole plus 5-fluorocytosine in three patients). One patient died of intestinal obstruction of unknown causes, and four patients were lost to follow-up. Treatment duration ranged from 8 weeks to 1.5 years; the mean time was $7.13 \pm 2.65$ months.

\section{Discussion}

Although PC is not rare in China, the misdiagnosis rate is high due to its nonspecific symptoms. ${ }^{7}$ Due to the potential risk of CNS cryptococcosis and long duration of antifungal therapy of at least 6 months as recommended by the guidelines of the Infectious Diseases Society of America, ${ }^{8}$ it is necessary to establish the diagnosis of PC as soon as possible. As each method has a distinct role, we often need to combine multiple methods to improve the diagnostic outcome.

It was reported that serum $\mathrm{CrAg}$ test has higher sensitivity in immunocompromised patients than in immunocompetent hosts. ${ }^{9}$ The sensitivity of serum CrAg test in HIV-negative patients with isolated $\mathrm{PC}$ is about of $25 \%-56 \% .^{10,11}$ In a study by Zhao et al on 48 patients with proven PC, the sensitivity and specificity of serum $\mathrm{CrAg}$ test were $64.58 \%$ and $85.71 \%$, respectively, as confirmed by LA test. ${ }^{12} \mathrm{~A}$ retrospective analysis of 76 immunocompetent patients with PC reported by Ye et al from China showed that the serum CrAg test sensitivity was $66.7 \%$ as confirmed by enzyme immunoassay (EIA). ${ }^{13}$ The main methods of testing for CrAg include LA test, EIA and CrAg LFA. The CrAg LFA is a rapid diagnostic dipstick test and a point-of-care test for the detection of $\mathrm{CrAg}$. The sensitivity and specificity of CrAg LFA have consistently been shown to be excellent in comparison to LA test. ${ }^{3,14}$ In 
Table 4 Data of the six cases with negative serum $\mathrm{CrAg}$ test

\begin{tabular}{|c|c|c|c|c|c|c|c|c|c|}
\hline \multirow{2}{*}{$\begin{array}{l}\text { Age } \\
\text { (years) }\end{array}$} & \multirow[t]{2}{*}{ Sex } & \multirow{2}{*}{$\begin{array}{l}\text { Underlying } \\
\text { disease }^{\mathrm{a}}\end{array}$} & \multirow[t]{2}{*}{ Symptom $^{b}$} & \multicolumn{3}{|l|}{ Imaging } & \multirow[t]{2}{*}{ Histopathology } & \multirow[t]{2}{*}{ Culture } & \multirow{2}{*}{$\begin{array}{l}\text { Day of } \\
\text { culture }\end{array}$} \\
\hline & & & & & Size $(\mathrm{mm})$ & Location & & & \\
\hline 63 & $M$ & No & Dry cough & $\begin{array}{l}\text { Nodule, } \\
\text { enlargement of } \\
\text { mediastinal lymph } \\
\text { node }\end{array}$ & $15 \times 13$ & Multiple & Chronic inflammation & $\begin{array}{l}\text { Cryptococcus } \\
\text { neoformans }\end{array}$ & 6 \\
\hline 42 & M & Hypertension & No & Nodule & $11 \times 9$ & Single & Granuloma & $\mathrm{N} / \mathrm{A}$ & N/A \\
\hline 43 & $F$ & $\begin{array}{l}\text { Post-thyroid } \\
\text { cancer surgery }\end{array}$ & No & Nodule & $15 \times 10$ & Single & Granuloma & Negative & N/A \\
\hline 18 & $M$ & No & Chest pain & Nodule & $18 \times 22$ & Single & Chronic inflammation & C. neoformans & 6 \\
\hline 57 & $F$ & No & No & $\begin{array}{l}\text { Consolidation, } \\
\text { enlargement of } \\
\text { mediastinal lymph } \\
\text { node }\end{array}$ & $16 \times 23$ & Single & Chronic inflammation & C. neoformans & II \\
\hline 50 & $M$ & B-type hepatitis & No & Nodule & $11 \times 7$ & Single & Chronic inflammation & C. neoformans & 15 \\
\hline
\end{tabular}

Notes: "No" indicates no underlying disease. "'No" indicates abnormal CT findings after routine physical examination.

Abbreviations: $\mathrm{CrAg}$, cryptococcal capsular polysaccharide antigen; $\mathrm{CT}$, computed tomography; F, female; M, male; N/A, not available.
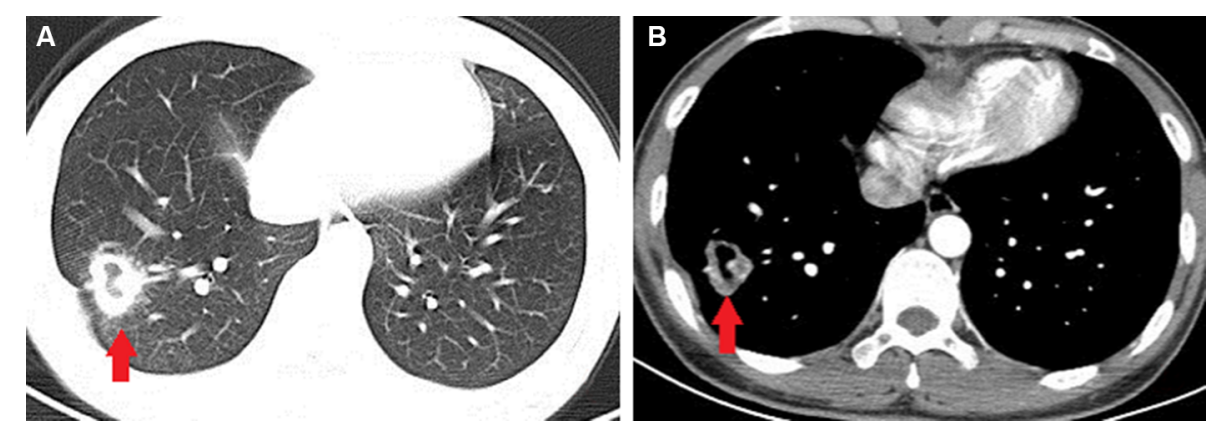

Figure 2 Chest CT scan of a 30-year-old female revealing a cavitary nodule, $25 \mathrm{~mm}$ in diameter, in the right lower lung (arrow).

Notes: (A) Lung window. (B) Contrast-enhanced CT of mediastinal window.

Abbreviation: CT, computed tomography.

Table 5 Diagnostic performance of different methods for PC

\begin{tabular}{|l|l|l|}
\hline Diagnostic method & $\begin{array}{l}\text { Positive, } \\
\text { n (\%) }\end{array}$ & $\begin{array}{l}\text { Negative, } \\
\text { n (\%) }\end{array}$ \\
\hline $\mathrm{CrAg}$ test in serum $(\mathrm{N}=89)$ & $83(93.3)$ & $6(6.7)$ \\
Histopathology in lung tissue $(\mathrm{N}=89)$ & $77(86.5)$ & $12(13.5)$ \\
Culture of lung tissue $(\mathrm{N}=65)$ & $46(70.8)$ & $19(29.2)$ \\
Smear of lung tissue $(\mathrm{N}=4 \mathrm{I})$ & $21(5 \mathrm{I})$ & $20(48.8)$ \\
\hline
\end{tabular}

Abbreviations: $\mathrm{CrAg}$, cryptococcal capsular polysaccharide antigen; $\mathrm{PC}$, pulmonary cryptococcosis.

2011, the WHO recommended that CrAg LFA together with LA test is an effective method for diagnosis of cryptococcal disease. Due to its requirement of less laboratory equipment and ability to provide stable results at room temperature, LFA has demonstrated usefulness as a point-of-care assay for diagnosis of cryptococcosis in developing countries. The sensitivity of serum CrAg test was $93.3 \%$ (83/89) in this study. Among six cases whose serum $\mathrm{CrAg}$ test was negative, the average nodule size was 1.2 (range $1.1-1.8$ ) $\mathrm{cm}$. When serum $\mathrm{CrAg}$ test is negative, $\mathrm{PC}$ diagnosis is challenging, and in such a case, histopathology and microbiological culture will help to confirm the disease. Histological forms of PC include intracapillary cryptococci, mucoid pneumonia, granulomatous pneumonia, discrete granuloma and fibrocaseous cryptococcoma. ${ }^{15}$ Histopathology has the advantage of being able to provide a rapid and typical diagnosis of PC when compared with culture. Lung tissue can be acquired by surgery, CT-guided percutaneous lung biopsy or transbronchial lung biopsy. Recently, CT-guided percutaneous lung biopsy has become the preferred method as the operation is relatively simple and less invasive. Compared with sample obtained by surgery, the sample obtained by CT-guided percutaneous lung biopsy is smaller and sometimes not big enough for periodic acid-Schiff and Gomori methenamine silver staining. The accurate sensitivity of small tissues in the diagnosis of PC is unknown; in the present study, the sensitivity was $86.5 \%$ (77/89), and the major histological form observed was granulomatous pneumonia. 
Culture of diseased tissue is common in immunocompromised hosts who are suspected to have pulmonary fungal infection. Some studies yielded a diagnostic rate of $50 \%-75 \% .{ }^{16}$ Due to the absence of underlying diseases and the presence of nonspecific symptoms, PC is often misdiagnosed as tumor or pneumonia initially. After biopsy, the tissue obtained is manually homogenized in sterile saline solution. The pelleted samples and the homogenate are used for culture and stain. The process is tedious and has high chance of contamination. Therefore, lung tissue obtained under CT guidance from immunocompetent hosts often shows negative results in mycological culture. The value of lung tissue culture in $\mathrm{PC}$ is not clear. Fisher et $\mathrm{al}^{17}$ identified 48 patients with PC confirmed by histopathology or mycological culture, of whom $29(60 \%)$ presented the organism in culture. It is unclear whether fungal organisms which are detected histopathologically in pulmonary tissue can be considered alive or dead. Therefore, it remains unclear whether immunocompetent patients who have histological evidence of $C$. neoformans from a lung biopsy, but negative cultures of the lung tissue, will respond to antifungal treatment. However, there are many factors that influence the culture results of lung tissue, such as the number of pathogens, the amount of NA, mixed infection of fungi and bacteria, previous antifungal agents administered, duration of culture and so on. In general, many fungal pathogens are characterized by slow multiplication; traditional mycological practice has mandated at least 10-14 days of incubation time for blood cultures. ${ }^{18}$ When the sample coexists with bacteria, once the bacteria grow, growth of the fungus is suppressed. In this study, the sensitivity of culture was $70.8 \%(46 / 65)$. All the 12 cases, whose histological examination of lung tissue failed to establish the diagnosis, had C. neoformans growth. The average time of Cryptococcus growth is $9.5 \pm 6.9$ days. PC coexisting with pulmonary carcinoma is rare. Harada et al reviewed 13 cases $^{19}$ and found that the lung cancers were all adenocarcinomas, located in the lower lobes with unknown causes. Coexistence of both lesions in a solitary tumor, as seen in the present case, is extremely rare. We speculated that pulmonary adenocarcinoma may be preceded by PC.

A limitation of our study is its retrospective nature. Not all the patients underwent microbiological culture examination after lung biopsy. Right now, a prospective study of PC is ongoing in our unit, and some of the questions may have answers in the future.

\section{Conclusion}

Because PC has nonspecific symptoms and often occurs without underlying diseases, clinicians may fail to make an early diagnosis of PC without HIV infection. Serum test is sensitive and rapid which can be used in both developing and developed nations. Histology has an important role in confirming PC, while culture obtained from the diseased tissue has a complementary role especially when histopathology cannot provide definite diagnosis. Biopsied lung tissue should be submitted for cultures whenever feasible. ${ }^{20}$

\section{Acknowledgment}

This work was supported by Natural Science Foundation of Zhejiang Province (LY15H010020).

\section{Disclosure}

The authors report no conflicts of interest in this work.

\section{References}

1. Liu K, Ding H, Xu B, et al. Clinical analysis of non-AIDS patients pathologically diagnosed with pulmonary cryptococcosis. J Thorac Dis. 2016;8(10):2813-2821.

2. Yuchong C, Fubin C, Jianghan C, et al. Cryptococcosis in China (1985-2010): review of cases from Chinese database. Mycopathologia. 2012;173(5-6):329-335.

3. Tang MW, Clemons KV, Katzenstein DA, Stevens DA. The cryptococcal antigen lateral flow assay: A point-of-care diagnostic at an opportune time. Crit Rev Microbiol. 2016;42(4):634-642.

4. Dohtsu Y, Ishimatsu Y, Takatani H, et al. [Clinical studies of sixteen cases with pulmonary cryptococcosis mainly with respect to serum level of cryptococcal antigen]. Kansenshogaku Zasshi. 2005;79(9):656-663. Japanese.

5. Ascioglu S, Rex JH, de Pauw B, et al. Defining opportunistic invasive fungal infections in immunocompromised patients with cancer and hematopoietic stem cell transplants: an international consensus. Clin Infect Dis. 2002;34(1):7-14.

6. Moore EH. Technical aspects of needle aspiration lung biopsy: a personal perspective. Radiology. 1998;208(2):303-318.

7. ZhangY, LiN, Zhang Y, et al. Clinical analysis of 76 patients pathologically diagnosed with pulmonary cryptococcosis. Eur Respir J. 2012;40(5): 1191-1200.

8. Perfect JR, Dismukes WE, Dromer F, et al. Clinical practice guidelines for the management of cryptococcal disease: 2010 update by the infectious diseases society of america. Clin Infect Dis. 2010;50(3): 291-322.

9. Lin TY, Yeh KM, Lin JC, Wang NC, Peng MY, Chang FY. Cryptococcal disease in patients with or without human immunodeficiency virus: clinical presentation and monitoring of serum cryptococcal antigen titers. J Microbiol Immunol Infect. 2009;42(3):220-226.

10. Pappas PG, Perfect JR, Cloud GA, et al. Cryptococcosis in human immunodeficiency virus-negative patients in the era of effective azole therapy. Clin Infect Dis. 2001;33(5):690-699.

11. Aberg JA, Mundy LM, Powderly WG. Pulmonary cryptococcosis in patients without HIV infection. Chest. 1999;115(3):734-740.

12. Zhao Y, Cai SX, Wang JL. Diagnostic Analysis of Primary Pulmonary Cryptococcosis in 90 HIV-negative Cases. Chinese Journal of Respiratory \& Critical Care Medicine. 2012. Available from: http://en.cnki.com. cn/Article_en/CJFDTotal-ZGHW201206012.htm. Accessed October 31, 2018.

13. Ye F, Xie JX, Zeng QS, Chen GQ, Zhong SQ, Zhong NS. Retrospective analysis of 76 immunocompetent patients with primary pulmonary cryptococcosis. Lung. 2012;190(3):339-346.

14. Vijayan T, Chiller T, Klausner JD. Sensitivity and specificity of a new cryptococcal antigen lateral flow assay in serum and cerebrospinal fluid. MLO: medical laboratory observer. 2013;4516(318):20. 
15. Mark EJ. Lung Biopsy Interpretation. Baltimore: Williams \& Wilkins; 1984.

16. Hsu JL, Kuschner WG, Paik J, Bower N, Vazquez Guillamet MC, Kothary $\mathrm{N}$. The diagnostic yield of CT-guided percutaneous lung biopsy in solid organ transplant recipients. Clin Transplant. 2012;26(4):615-621.

17. Fisher JF, Valencia-Rey PA, Davis WB. Pulmonary Cryptococcosis in the Immunocompetent Patient-Many Questions, Some Answers. Open Forum Infect Dis. 2016;3(3):ofw167.
18. Bosshard PP. Incubation of fungal cultures: how long is long enough? Mycoses. 2011;54(5):e539-e545.

19. Harada T, Hakuma N, Kamimura A, Ito K, Okamoto K. Pulmonary cryptococcosis within a pulmonary carcinoma-review of reported cases. Intern Med. 2006;45(6):369-372.

20. Mukhopadhyay S. Role of histology in the diagnosis of infectious causes of granulomatous lung disease. Curr Opin Pulm Med. 2011;17(3): 189-196. 


\section{Supplementary material}

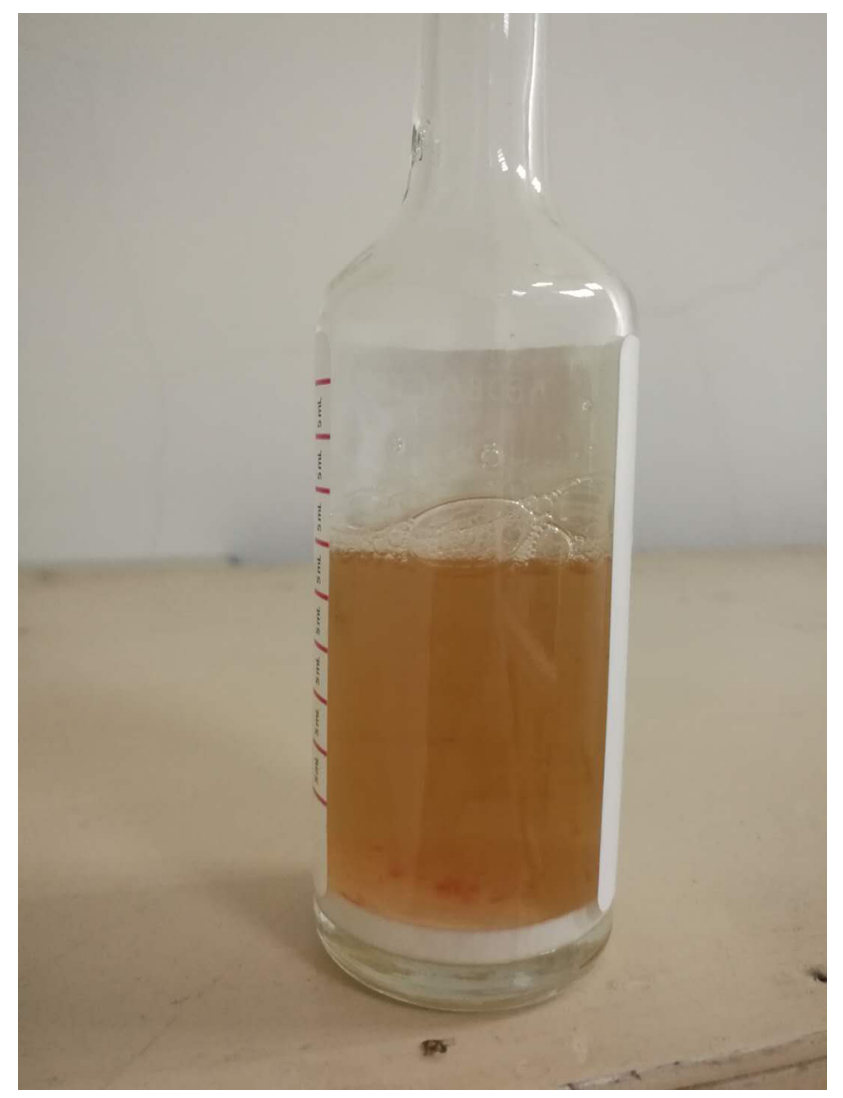

Figure SI The liquid obtained from the aspiration was inoculated into the bottles of the Bactec for bacterial, fungal and mycobacterial culture.

\section{Publish your work in this journal}

Infection and Drug Resistance is an international, peer-reviewed openaccess journal that focuses on the optimal treatment of infection (bacterial, fungal and viral) and the development and institution of preventive strategies to minimize the development and spread of resistance. The journal is specifically concerned with the epidemiology of antibiotic resistance and the mechanisms of resistance development and diffusion in both hospitals and the community. The manuscript management system is completely online and includes a very quick and fair peerreview system, which is all easy to use. Visit http://www.dovepress.com/ testimonials.php to read real quotes from published authors.

Submit your manuscript here: https://www.dovepress.com/infection-and-drug-resistance-journal 